\title{
A Case of Acute Stress in Post-hypnotized Patient
}

\author{
Cut Rika Pratiwi(D), Elmeida Effendy*(D), Muhammad Surya Husada (iD \\ Department of Psychiatry, Faculty of Medicine, Universitas Sumatera Utara, Medan, Indonesia
}

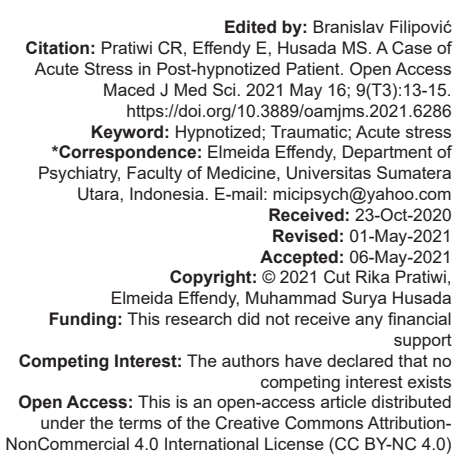
Edited by: Branislav Filipović
Citation: Pratiwi CR, Effendy E, Husada MS. A Case of Acute Stress in Post-hypnotized Patient. Open Access Maced J Med Sci. 2021 May 16; 9(T3):13-15 https://doi.org/10.3889/oamjms.2021.6286
Keyword: Hypnotized; Traumatic; Acute stress Keyword: Hypnotized; Traumatic; Acute stress
Correspondence: Elmeida Effendy, Department of Psychiatry, Faculty of Medicine, Universitas Sumater Utara, Indonesia. E-mail: micipsych@yahoo.com Received: 23-Oct-2020 Revised: 01-May-2021 Accepted: 06-May-2021
Copyright: $\odot 2021$ Cut Rika Pratiwi Copyright: @ 2021 Cut Rika Pratiwi,
Elmeida Effendy, Muhammad Surya Husada Funding: This research did not receive any financial Competing Interest: The authors have declared that no competing interest exist Open Access: This is an open-access article distributed under the terms of the Creative Commons Attribution-
NonCommercial 4.0 International License (CC BY-NC 4.0)

\begin{abstract}
BACKGROUND: Mental health conditions that can occur immediately after a traumatic event are called acute stress reaction, in this case, happen after hypnosis. This can cause a variety of psychological symptoms without attention or treatment, cause post-traumatic stress disorder. The psychological symptoms can negatively affect the quality of life, especially the reactions arise after a traumatic event that after being hypnotized. Hypnosis works by changing the activity in brain regions associated with attention or alertness. At the time hypnotized, we saw a very high level of concentration so that suggestions given to him will be more easily accepted.

CASE REPORT: The case presented is the hypnotic impact of acute stress reactions occurred in Mrs. J, a 63 year old woman from Karo ethnic group who experienced anxiety, fear, and difficulty sleeping after hypnotic procedure 4 days ago. This experienced it after being hypnotized at home.

CONCLUSION: Hypnosis plays a role in all parts of life involving human mind. Hypnosis is a science that exploits the potential mental and hidden in humans, known as the subconscious. In medical health, hypnosis therapy is very important, what we need to realize is that hypnosis with bad intentions can harm humans. Hypnosis incident was reported in patients who suffer from post-traumatic stress disorder. Particularly women. Older women are more vulnerable to acute stress. Previous research has shown that hypnotic susceptibility correlated with personality traits.
\end{abstract}

\section{Introduction}

An acute stress reaction is a quite severe temporary disorder that occurs in individuals even without any menta; disorder in response to the physical and psychological stress. This condition commonly disappears within a few hours or days [1].

Stressors can be a traumatic experience extraordinary, which can include a serious threat to the security or physical integrity of an individual or loved ones (e.g., catastrophic natural disasters, accidents, war, assault crimes, and rape), or a change unusual and changes that threaten social position and/or the relationship of the relevant networks, such as grief barrage or fire. The risk of these disorders may increase if there are physical exhaustion or organic factors (e.g., the elderly) [1].

Effects of stress: Moderate stress causes an increase in adrenaline, which increases learning and memory, and also severe stress inhibits knowledge and memory [2].

The prevalence of acute stress disorder in a population recently exposed to trauma (e.g., within 1 month of exposure to trauma) varies according to the nature of the event and context are rated. In both the US and non-US populations, acute stress disorder is identified in less than $20 \%$ of cases after a traumatic event that does not involve violence between; $14 \%$ of mild traumatic brain injury, $13-21 \%$ of motor vehicle accidents, $19 \%$ of the attacks, $6-12 \%$ of industrial accidents, and $10 \%$ of severe burns. A higher level (e.g., 20-50\%) was reported following interpersonal traumatic events, rape, including assault, and witnessed the mass shooting [1].

\section{Case Report}

An old woman $63^{\text {th }}$ named Mrs. J came with his son to the University Hospital of North Sumatra with complaints of restless it was experienced for 4 days ago accompanied by insomnia, decreased concentration, not excited, reduced appetite, taste excessive fear, guilt, and suspicion against anyone.

Mrs. J lives with her son, her husband was died 3 years ago. She is spoiled, other character with her is easy to trust people, unable to make decisions, not confident, and always depends on other people.

On Saturday afternoon, when she's home alone. Her son goes out for buying some food near from their house. Female guests arrived with features of fair skin, brown hair, beautiful faces, and flawless. She is looking for a rent house. Mrs. J offers to rent her house 5 million for a year to that woman. At that time, she did not have cash money to pay the rent house. She only has 
fake gold jewelry and Mrs. J thought that it was real gold. Then, she said that if the jewelry was to be resold, she would have a higher price than your rent house price.

She was an expert at exploiting the situation, she whispered Mrs. $J$ to took all the gold jewelry and money. Mrs. J agreed, without much thinking Mrs. J takes everything that is kept in her house and give it all to her than she left.

A few moments later, Mrs. J's son came home, he was surprised to see his mother with the confused face and the house looked very messy. He was very shocked and did not know what happen with mother. She called his mother and tapped her on the shoulder. Suddenly, Mrs. J screamed, cried, and realized that she had actually been hypnotized by a woman who she did not know her well.

Mrs. J tells what happened to her son. She has been hypnotized, all hers have been taken by that woman. She was scared, shocked, helpless. Since this incident, a few days later, she started uncomfortable feeling, very annoying and accompanied by various additional symptoms.

During the interview, we found the appearance of a weak posture, well-dressed, a healthy physical health, normoaktif psychomotor activity, cooperative attitude toward the examiner, in accordance affective and dysphoric mood, more emotional anxiety. Not encountered the content of thought disorder and perceptual disturbances, compos mentis, good concentration, insight degrees 6, social and personal judgment always felt guilty, she also had dependent personality. On internal examination, we found affect: Appropriate, mood: Dysphoric, other emotion: Anxiety, speech: Relevant, thought process: Good, perception: Ungood, concentration: Bad impulse, control: Ungood - drug laboratory tests (urine test) negative. There is no acute stress disorder before. There is no family history of anxiety or other psychiatric disorder.

\section{Discussion}

The hypothesis that hypnosis is a state of consciousness characterized by a lack of spontaneous behavior was tested by determining whether the hypnotized subject could simulate awake behavior. If hypnosis shows altered states of consciousness, the simulated subject may not be able to simulate alert and awake states. Thus, the purpose of hypnotized can be more easily achieved because someone are very focused on the content of suggestions received [3].

Hypnotic susceptibility is the ability to respond to suggestions for changes in subjective experience and to changes in perception, sensation, emotions, thoughts, or behavior. Ability showed descent tendency and the remains stable during the lifetime of an individual. Some people with high levels of concentration can be suggestible, impressionable and hypnosis can also correlate with personality traits. Personality traits are said to predispose a person to being hypnotized easily and with difficulty. High hypnotizables reported to have increased accessibility to show exaggerated affective and emotional feelings [4].

To diagnose acute stress reaction, there must be a direct link and a definite time between the incidence extraordinary stressors experience with the onset of symptoms; onset is usually after a few minutes or even immediately after the incident. Also found symptoms: There is a mixed picture of symptoms that typically changeable; in addition to symptom onset that circumstances "glued" ("Daze"), all of the following symptoms may appear: Depressive, anxiety, anger, disappointment, overactivity, and withdrawal, but no one of these symptoms which dominate the clinical picture for a long time. In cases that can be diverted from the scope of the stressor, symptoms may disappear quickly (the longest in a few hours), in the case, where stress is sustained or not transferable; the symptoms are usually just beginning to subside after 24-48 $\mathrm{h}$ and usually almost disappeared after 3 days [5].

Higher hypnotic susceptibility has been reported in patients suffering from post-traumatic stress disorder. Stress levels are higher among women aged 35-44 years than men, and this is consistent with a study that women experience higher levels of stress than men because women are more likely to care for children, housekeeping, and work, along with physical conditions as well as psychological stress from pregnancy and childbirth [4], [6].

There is an explanation about hypnosis causing imaginal exposure. First, hypnosis with acute stress disorder causes dissociative disorders and may experience various symptoms such as multiple personalities. Second, the social psychological theory of hypnosis presupposes the main mechanisms that mediate the hypnotic response induced by the increased suggestion associated with hypnotic techniques. Third, contributing to decreased anxiety, hypnosis can make someone who is hypnotized calmer and relax muscles [7].

It is hard to know the difference between acute effects and conditions of ongoing stress can hamper efforts to understand the mechanisms that depression results from stressfully. Many studies stress-depression questionnaire and checklist do not clearly differentiate between acute and chronic stress [8]

Stress management has received increasing attention and clinical importance. One way is to do hypnotherapy and modern clinical hypnotherapy which has become increasingly popular and get more attention around the world in recent years [9].

There are several reasons to anticipate that the induction of hypnosis should not be a very interesting topic or promising. However, there is also some reason to believe that the induction of hypnosis might, on the contrary, the topic is very interesting and promising. In the medical condition, the hypnotized is defined as "a state of consciousness that involve focused attention and impaired 
peripheral consciousness characterized by an increased capacity to respond to the suggestion," hypnotherapy is defined as "the use of hypnosis in the treatment of medical disorders or psychological or concern" and also includes the use of conversational language hypnosystemic therapy and attitudes that enable resource and serviceoriented solutions. However, in this case, hypnosis misused for things that are not true [9], [10].

Cognitive-behavioral methods and methods to reduce stress-based consciousness have been thoroughly researched for ice effective and the benefits of stress reduction. Some trainings of cognitivebehavioral stress management are based on evidence. Compared with those approaches, the clinical effects of hypnotherapy for stress reduction method are still under investigation by the poor, although there are many kinds of practical literature to teach herpes psychotherapy practice hypnosis for stress management intervention [9].

Hypnotherapy useful for the clinical research for stress reduction approaches, especially use of psychotherapeutic interventions, how effectiveness is measured, outcomes assessed, and what the effects are observed [9].

Psychological disorders and diseases associated with stress are considered essential health problems worldwide. Selye one of the pioneers of the study of stress found "no reaction integrated adaptive reactions are strongly associated with non-specific stress itself," is called "Adaptation Works Syndrome." It develops in three stages: "Alarm Reaction," Resistance stage, and the stage of exhaustion in the biological meaning, stress is the interaction between the damage and defense. In addition to the independent effect of acute stress disorder risk factors, the interaction between biological factors, psychological, social, and identified further can change the odds of developing acute stress disorder and also need additional study [9], [11]. Based on that it is necessary to know stress management. who can reduce stress and find the best solution if we get the problems in the future.

\section{Conclusion}

Hypnosis plays a role in all part of life that involves the human mind. Hypnosis is a science that exploits the mental potential and is hidden in humans, which is known as the subconscious. Such as belief, passion, desire, conscience, imagination, sense experience, memory, and other potentials.

In the past, hypnosis used what was considered mystical, criminal with the aim of harming others. At present, hypnosis is widely used for medical purposes, especially by surgeons and dentists to create an anesthetic effect without using anesthetic. Hypnosis is also potentially capable of treating mental disorders, controlling emotions, managing stress, and regulating the subconscious mind.

Hypnosis therapy is good for medical health, we need to be aware of is hypnosis with bad goals that can harm people. The incidence of hypnosis was reported more in patients suffering from posttraumatic stress disorder. Particularly in women. Elderly women are more prone to acute stress. Previous research has shown that hypnotic susceptibility correlated with the personality traits.

\section{References}

1. Arlington VA. American Psychiatric Association: Diagnostic and Statistical Manual of Mental Disorders, DSM-5. $5^{\text {th }}$ ed. Washington, DC: American Psychiatric Association; 2013. p. 281-6. https://doi.org/10.1007/springerreference_179660

2. Wang WW. Comprehensive Psychiatry Review. St. Louis, Missouri: Olivette Institute; 2010.

3. Joseph R. The American Journal of Clinical Hypnosis, Printed in USA "Can Hypnotized Subjects Waking Simulate Behavior? Vol. 16. United States: Michigan State University; 1973. https://doi. org/10.1080/00029157.1973.10403648

4. Yu E, Zhu J, Tan Y, Liao Z, Qiu Y, Zhang B, et al. Color preferences in participants with high or low hypnotic susceptibility. Neuropsychiatr Dis Treat. 2018;14:393-8. https:// doi.org/10.2147/ndt.s154887

5. American Psychiatric Association. Diagnostic and Statistical Manual of Mental Disorder. $3^{\text {rd }}$ ed. Washington, DC: American Psychiatric Association; 1987.

6. Kim YS, Kim HN, Lee JH, Kim SY, Jun EJ, Kim JB. Association of stress, depression, and suicidal ideation with subjective oral health status and oral functions in Korean adults aged 35 years or more. BMC Oral Health. 2017;17(1):101. https://doi. org/10.1186/s12903-017-0391-4 PMid:28645271

7. Bryant RA, Moulds ML, Guthrie RM, Nixon RD. The additive benefit of hypnosis and cognitive-behavioral therapy in treating acute stress disorder. J Consult Clin Psychol. 2005;73(2):33440. https://doi.org/10.1037/0022-006x.73.2.334 PMid:15796641

8. Hammen C, Kim EY, Eberhart NK, Brennan PA. Chronic and acute stress and the prediction of major depression in women. Depress Anxiety. 2009;26(8):718-23. https://doi.org/10.1002/da.20571 PMid:19496077

9. Fisch S, Brinkhaus B, Teut M. Hypnosis in patients with perceived stress-a systematic review. BMC Complement Altern Med. 2017;17(1):323. https://doi.org/10.1186/s12906-017-1806-0 PMid:28629342

10. Shaw RJ, Bernard RS, Deblois T, Ikuta LM, Ginzburg K, Koopman C. The relationship between acute stress disorder and posttraumatic stress disorder in the neonatal intensive care unit. Psychosomatics. 2009;50(2):131-7. https://doi.org/10.1176/appi.psy.50.2.131 PMid:19377021

11. Ursano RJ, Bell C, Eth S, Friedman M, Norwood A, Pfefferbaum B, Pynoos JD, et al. Practice guideline for the treatment of patients with acute stress disorder and posttraumatic stress disorder. Am J Psychiatry. 2004;161 Suppl 11:3-31. https://doi.org/10.1176/ appi.books.9780890423479

PMid:1561751 